\title{
The processing of non-anticipated information in financial markets: Analyzing the impact of surprises in the employment report *
}

\author{
Nikolaus Hautsch ${ }^{\dagger}$ and Dieter Hess ${ }^{\ddagger}$
}

January 2002

\begin{abstract}
This paper delineates the simultaneous impact of non-anticipated information on mean and variance of the intraday return process by including appropriate variables accounting for the news flow into both the mean and the variance function. This allows us to differentiate between the consistent price reaction to surprising news and the traders' uncertainty about the precise price impact of this information. Focussing on the US employment report, we find that headline information is almost instantaneously incorporated into T-bond futures prices. Nevertheless, large surprises, and 'bad' news in particular, create considerable uncertainty. In contrast, if surprises in related headlines cross-validate each other, less room for differences of opinion is left, and hence volatility is decreased.
\end{abstract}

Keywords: $\quad$ high-frequency data; information processing; macroeconomic JEL classification: $\quad$ E44, G14

\footnotetext{
${ }^{*}$ For valuable comments we are grateful to Ben Craig, Günter Franke, Stefan Klotz, Michael Lechner, Winfried Pohlmeier, and Harris Schlesinger. We thank as well Simon Benninga, the editor of the European Finance Review, and an anonymous referee who greatly helped to improve the paper. This paper has also benefited from comments of workshop participants at the Universities of Konstanz and St. Gallen. Data on analysts' forecasts were generously provided by Standard \& Poors Global Markets. The authors gratefully acknowledge financial support by the Deutsche Forschungsgemeinschaft (DFG) within the Center of Finance and Econometrics (CoFE). Dieter Hess appreciates a grant by the DFG (project HE 3180/1).

${ }^{\dagger}$ University of Konstanz, Center of Finance and Econometrics. Tel: +49 7531882204 , e-mail: nikolaus.hautsch@uni-konstanz.de

${ }^{\ddagger}$ Corresponding author. University of Konstanz, Center of Finance and Econometrics, Universitätsstr. 10, Box D-147, 78457 Konstanz, Germany. Tel: +49 7531 883164, e-mail: dieter.hess@uni-konstanz.de
} 


\section{Introduction}

This paper investigates the processing of macroeconomic news in financial markets, in particular surprises in headline figures of the US employment report. We model simultaneously two effects of public news arrival: On the one hand, non-anticipated information in public news induces a shift in traders' beliefs about the equilibrium price level which should result in a sharp and immediate price reaction. While average beliefs shift instantaneously, on the other hand, traders do not have to agree about the precise price impact of a given piece of information. Uncertainty about the new equilibrium price level causes prices to fluctuate more widely around the new equilibrium level until a new consensus is reached. We disentangle these effects by controlling for the impact of non-anticipated information on both the mean and the variance function of the return process.

As it is well known from previous literature on this topic, information arrival has an impact on both prices and volatility in financial markets (see e.g., Goodhart and O'Hara 1997 for an overview). ${ }^{1}$ Nevertheless, previous empirical studies on announcement effects have either focused on the impact of scheduled announcements on signed returns (e.g. Berkman 1978, Urich and Wachtel 1984, Hardouvelis 1988, Fleming and Remolona 1997, and Hess 2001) or on the volatility of returns (e.g. Harvey and Huang 1991, Ederington and Lee 1993, Fleming and Remolona 1999a, and Franke and Hess 2000a) neglecting relations between the impact of non-anticipated information on the first and second moments of the return process. ${ }^{2}$ We close this apparent gap in the literature by modelling the impact of announcements on both the mean and the variance function simultaneously. Our approach provides some interesting insights into the processing of information. It enables us to

\footnotetext{
${ }^{1}$ There is also some tradition using volatility as a proxy for information arrival. See, e.g. Lamoureux and Lastrapes (1990) or Franke and Hess (2000b).

${ }^{2}$ Note that a few studies investigate both signed returns and absolute returns, as well as some other variables such as trading volume or bid-ask spreads. For example, Fleming and Remolona (1997) run separate regressions of signed returns on surprises as well as of absolute returns and trading volume on announcement dummies and absolute surprises. See also Balduzzi, Elton, and Green (1997). Nevertheless, these studies do not model the simultaneous impact of announcements on first and second moments.
} 
distinguish between a volatility shock arising from a news induced shift of the price to a new equilibrium and a situation in which prices are just bouncing around, for example because traders' opinions diverge widely.

We use high-frequency data of the Chicago Board of Trade (CBOT) T-bond future in order to investigate the effects of news arrival. One problem in this context is the simultaneous occurrence of releases. To avoid an interference of effects caused by multiple releases, we analyze situations in which only one report is announced at a time. In particular, we focus on the employment report, which is typically released at 8:30 a.m. ET (Eastern Time). Besides being the most influential report, ${ }^{3}$ it has the nice property that the overlap with other announcements is minimal. During the five-year sample used here, i.e. January 1995 to December 1999, only 7 out of the 60 employment announcement days are lost due to an announcement of other releases at the same time. In order to keep the results free from the influence of announcements made later on during the same day (in particular at 10:00 a.m.), we focus on a 90-minute window in which information processing should be dominated by the release of the employment report. ${ }^{4}$ In contrast to Andersen and Bollerslev (1998) who model the 24-hour volatility pattern in the foreign exchange market and try to identify the main components of 'overall' volatility, we focus on 90-minute subsamples around announcements in order to analyze the processing of important macroeconomic information and in particular its simultaneous impact on the mean and the variance of T-bond futures returns.

The effects of information arrival are analyzed by means of an intraday ARCH model with multiplicative heteroskedasticity on 2-minute returns. Explanatory variables which capture the time pattern and the impact of surprises are included in the mean function as well as

\footnotetext{
${ }^{3}$ Several studies document that the employment report has by far the highest impact on the mean function (e.g. Balduzzi, Elton, and Green 1997, Hess 2001) as well as on the variance function (Ederington and Lee 1993, Fleming and Remolona 1997).

${ }^{4}$ To provide a simple robustness check for our results, we also analyze information processing around some other important reports, i.e. the announcement of the NAPM index, consumer prices, and housing starts.
} 
in the variance specification. In order to analyze the explanatory power of the different model components, their predictive performance is evaluated separately. This allows us to differentiate between the explanatory power of the implemented ARCH component, the variables capturing deterministic time patterns, and the additional explanatory variables, i.e. surprises in headline figures.

Based on this estimation approach, we provide the following main findings: Nonanticipated information leads to a sharp and consistent price reaction suggesting that traders' average beliefs shift almost instantaneously. Nevertheless, after controlling for the effect on the mean we still find a strong and persistent increase in volatility which points to considerable disagreement among traders about the precise implications of macroeconomic news. These differences of opinion are only slowly resolved. Furthermore, we delineate the different modes of impact of non-anticipated information on volatility: We provide some evidence that traders' differences of opinion increase with the magnitude of a surprise (absolute volatility impact). 'Bad' news create considerably more uncertainty among traders than 'good' news (asymmetric impact). Surprises in related headline figures pointing in the same direction reinforce the price signal, and thus leave less room for differences of opinion (reinforcement effect).

The remainder of this paper is organized as follows. The subsequent section reviews the related literature. Section 3 characterizes the major information components of the employment report. Moreover, several hypotheses are derived concerning the processing of outstanding information. Section 4 describes the data, explains the estimation procedure, and presents the empirical results. In section 5 we analyze the information processing around some other announcements in order to check the robustness of the results. Section 6 concludes. 


\section{Previous studies - a synthesis}

The previous literature on announcement effects can be divided into two branches, one focussing on the impact of news on first moments, the other focussing on second moments of the price process. The first branch analyzes the signed price impact of non-anticipated information. The main question of this literature is which types of announcements significantly affect the equilibrium price level. Usually, these studies measure the magnitude of surprises employing survey data on analysts' forecasts for certain headline figures contained in macroeconomic reports. Non-anticipated information is then measured by the deviation of a given headline figure $\left(A_{\tau}\right)$ announced at time $\tau$ from the median of analysts' forecasts $\left(F_{\tau}\right)$. Hence, the surprise in the $i$ th headline figure is given as $S_{i, \tau}=A_{i, \tau}-F_{i, \tau}$. Typically, the impact on the return in period $t$ is investigated by regressing signed log returns $r_{t}$ on surprises in some set of macroeconomic announcements $(i=1, \ldots, n)$, i.e.

$$
r_{t}=\alpha_{0}+\sum_{i=1}^{n} \alpha_{i} S_{i, \tau} D_{i, t=\tau}+\varepsilon_{t},
$$

where $D_{i, t=\tau}$ denotes headline specific dummy variables which take on the value 1 if announcement $i$ is made during the interval $t$, and 0 else. In addition, lagged returns or variables controlling for seasonalities such as day-of-the-week effects may be included in such an analysis. ${ }^{5}$ Heteroskedasticity in the error term $\varepsilon_{t}$ is usually not explicitly modelled. Instead, heteroskedasticity consistent variance-covariance estimators are applied.

While early studies analyze daily returns, ${ }^{6}$ more recent studies regress returns in narrow intraday windows around the announcements on surprises in headline figures in order to separate the impact of scheduled announcements from other not explicitly observed news which may arrive occasionally over the course of a trading day. Following this approach, Becker, Finnerty, and Kopecky (1996), Fleming and Remolona (1997, 1999b), and Hess

\footnotetext{
${ }^{5}$ See, for example, Fleming and Remolona (1997) or Hess (2001).

${ }^{6}$ See, for example, Berkman (1978), and Urich and Wachtel $(1981,1984)$ who analyze money growth announcements. Cook and Korn (1991) and Prag (1994) focus on employment reports. Hardouvelis (1988), Dwyer and Hafer (1989), and Edison (1996), among others, investigate several releases.
} 
(2001), among others, find that several US announcements have a significant influence on bond market prices. Evidence of announcement effects in the foreign exchange spot market is provided, for example, by Almeida, Goodhart, and Payne (1998) and Dominguez (1999). ${ }^{7}$ Overall, studies on first moments suggest a significant and immediate adjustment of the level of prices to non-anticipated information. In particular, surprising information in the employment report (especially in the nonfarm payrolls figure) triggers the most pronounced price responses in both bond and foreign exchange markets.

A second string of the literature on announcement effects analyzes volatility shocks due to news arrival. First of all, these studies show that scheduled macroeconomic announcements stand out from the steady flow of information which hits financial markets. Fleming and Remolona (1997) find that out of the 25 largest intraday price changes in the U.S. treasury market all but one occurred after such an announcement, in particular after the release of employment reports. This is confirmed by Bollerslev, Cai, and Song (2000) for T-bond futures, and Dominguez (1999) obtains similar results for the Deutsche Mark-US Dollar spot rate. ${ }^{8}$

In contrast to studies focussing on the mean function, the literature on second moments usually does not account for surprises in releases. In general, the impact of the mere existence of an announcement is investigated, for example, by regressing absolute log returns, $\left|r_{t}\right|$, on the above defined dummy variables which account only for the timing of announcements, i.e. ${ }^{9}$

$$
\left|r_{t}\right|=\alpha_{0}+\sum_{i=1}^{n} \alpha_{i} D_{i, t=\tau}+\nu_{t} .
$$

\footnotetext{
${ }^{7}$ See also Goodhart, Hall, Henry, and Pesaran (1993) who analyze the influence of two single news events on high-frequency British Pound-US Dollar exchange rates.

${ }^{8}$ However, it is not clear whether these findings are due to consistent price reactions to new information or just volatility shocks, since these approaches do not explicitly control for shifts of the mean function.

${ }^{9}$ See, for example, Ederington and Lee (1993) or Fleming and Remolona (1997). In general, seasonalities in volatilities such as day-of-week or time-of-the-day effects are controlled for by including appropriately defined additional dummy variables.
} 
Based on such specifications several studies document that quite a number of different types of releases have a significant impact on (intraday) volatility, for example, Ederington and Lee (1993), Franke and Hess (2000a) for T-bond futures, Fleming and Remolona (1997) and Balduzzi, Elton, and Green (1997) for the interdealer T-bond market, and Harvey and Huang (1991) and Ederington and Lee $(1993,1995)$ for foreign exchange spot and futures markets.

The persistence of volatility after such an announcement is another issue which has gained widespread attention. Analyzing daily returns, Jones, Lamont, and Lumsdaine (1998) as well as Jones (1998) apply a switching GARCH model and find no significantly higher interday volatility persistence after the release of the employment report and the producer price index. In contrast, disentangling dynamic GARCH effects and announcement effects on the basis of a filtered GARCH model, Li and Engle (1998) are able to reject the hypothesis that volatility persistence that stems from announcement days is the same as from non-announcement days. Ederington and Lee (1993), for example, analyze the sample variance in 5-minute intervals across announcement days and find that volatility is significantly higher in the period associated with the announcement and that it declines rapidly afterwards. This is confirmed for several markets by various other studies (e.g. Ederington and Lee 1995, Crain and Lee 1995, Balduzzi, Elton, and Green 1997, Fleming and Remolona 1999a, and Franke and Hess 2000a). ${ }^{10}$

A detailed characterization of different volatility components, including calendar features, scheduled announcement effects as well as persistent volatility $(\mathrm{ARCH})$ components, in the Deutsche Mark-US Dollar foreign exchange spot market is provided by Andersen and Bollerslev (1998). They assume that the mean adjusted return process is given by

$$
R_{t, d}-\mathrm{E}\left[R_{t, d}\right]=\sqrt{h_{t, d}} u_{t, d}, \quad t=1 \ldots, T, \quad d=1, \ldots, D
$$

\footnotetext{
${ }^{10}$ Volatility seems to persist somewhat longer in more liquid instruments (see Christie-David and Chaudhry 1999).
} 
where $R_{t, d}=\exp \left(r_{t, d}\right)$ denotes gross returns and $u_{t, d}$ is an i.i.d. zero mean, unit variance error term. Since Andersen and Bollerslev explicitly specify daily ARCH-effects, the index $d$ is introduced to denote trading days. The variance process is specified by

$$
h_{t, d}=\sigma_{t, d}^{2} \cdot s_{t, d}^{2}
$$

where $\sigma_{t, d}^{2}$ collects the persistent volatility components which are modelled based on GARCH processes on a daily and intradaily level ${ }^{11}$ and $s_{t, d}^{2}$ represents intraday and interday seasonality components including also announcement effects.

Andersen and Bollerslev (1998) illustrate the identification and estimation of the different volatility components and evaluate their explanatory power. By discussing the major driving forces of the volatility process, they conclude that announcement effects are of minor importance when the overall volatility in the 24-hour foreign exchange market is modelled. Nevertheless, they show that major announcements lead to the largest returns and induce a strong response of the price process immediately after the release. ${ }^{12}$

Overall, studies focusing on volatility do not account for the consistent price reaction to non-anticipated information arrival which is well documented by studies on the mean process. Usually, second moments studies are concerned with volatility forecasting, mainly from a pre-announcement perspective, or with the identification of volatility components in order to characterize the driving forces of the overall volatility process. However, an important question is whether the observed volatility spike after macroeconomic announcements is merely due to a news induced jump of the price to a new equilibrium level.

In contrast to Andersen and Bollerslev (1998) or Bollerslev, Cai, and Song (2000), our major objective is not the characterization of the different components of overall volatility.

\footnotetext{
${ }^{11}$ In particular, Andersen and Bollerslev model $\sigma_{t, d}^{2}$ based on a daily GARCH process which is assumed to be constant over a trading day. Hence, $\sigma_{t, d}^{2}=\sigma_{d}^{2} / T$.

${ }^{12}$ Based on this framework (see also Andersen and Bollerslev 1997), Bollerslev, Cai, and Song (2000) investigate intraday seasonal patterns in volatility after controlling for interday GARCH effects and find supporting evidence for the T-Bond futures market.
} 
Instead we focus on the processing of non-anticipated information in scheduled announcements. Therefore, our approach differs with respect to two aspects: First, we control for the price impact of non-anticipated information by including appropriate news flow variables into the mean function. Second, we do not study the 24-hour trading process. Instead, we cut out narrow time periods around announcements in which we can identify the dominant news items. Using only those periods in which we can avoid an interference with other news releases, we have information on the timing of the news arrival but also on the amount and the sign of surprises. We assume the following process for 2-minute log returns:

$$
r_{t}-\mathrm{E}\left[r_{t}\right]=\sqrt{h_{t}} \cdot u_{t}
$$

with

$$
h_{t}=\sigma_{t}^{2}+s_{t}^{2},
$$

where, following the notation of Andersen and Bollerslev (1998), $s_{t}^{2}$ and $\sigma_{t}^{2}$ capture ARCH and announcement effects, respectively. The expectation $\mathrm{E}\left[r_{t}\right]$ is specified by $\mathrm{E}\left[r_{t}\right]=x_{t}^{\prime} \beta$, where $\beta$ is a coefficient vector and $x_{t}$ denotes the corresponding vector of explanatory variables (see section 4 for more details on the specific definition of the variables). In contrast to Andersen and Bollerslev (1998), we do not include any daily GARCH effects in the variance equation since we do not focus on a 24-hour period but on narrow time windows around announcements. ${ }^{13}$ Ignoring the daily GARCH component seems to be reasonable because we analyze announcements on a monthly schedule. ${ }^{14}$ Moreover, the announcement effects are very large relative to the interdaily GARCH effects. However, there is a heteroskedasticity component which is ignored in this analysis, and thus it is crucial to use robust inference techniques. $\sigma_{t}^{2}$ is simply specified by $\sigma_{t}^{2}=\sum_{j=1}^{p} \phi_{p} \varepsilon_{t-j}^{2}$, accounting for intradaily ARCH effects. The volatility component $s_{t}^{2}$ is specified as $s_{t}^{2}=$

\footnotetext{
${ }^{13}$ For this reason we drop the daily index $d$.

${ }^{14}$ For more details see section 4 .
} 
$\exp \left(w_{t}^{\prime} \gamma\right)$, including absolute surprises as well as signed surprises in the individual headline figures of the employment report (see section 4 for more details). Estimating equations (3) and (4) simultaneously, our approach may be viewed as a synthesis of the previous literature on the mean and the variance of the return process.

\section{Information diffusion in efficient markets}

What is it that makes markets react so sharply to macroeconomic announcements? How does the price adjustment process to non-anticipated information work? In order to analyze these and other questions, first the information content of the major headline figures of an employment report is described. Hypotheses concerning the impact of this information on the mean and variance of returns are presented thereafter.

\subsection{The information content of the employment report}

Several studies have documented that the monthly report on the U.S. employment situation prepared by the Bureau of Labor Statistics (BLS) is the most influential macroeconomic release for financial markets. ${ }^{15}$ Its importance stems from the fact that it is an extremely timely and comprehensive measure of economic activity. Nonfarm payroll employment, for example, is commonly seen as a coincident indicator of the business cycles. ${ }^{16}$ Moreover, both payroll employment and the unemployment rate provide a measure for the tightness of the labor market and thus an indication of price pressures in probably the most important input factor, i.e labor.

The employment report is a rather voluminous document containing a large amount of detail information. This is one of the reasons why previous studies have focused on headline figures which summarize this information. Another reason is the availability of so-called

\footnotetext{
${ }^{15}$ See, for example, Bollerslev, Cai, and Song (2000) or Fleming and Remolona (1999a) for its impact on intraday volatility and Fleming and Remolona (1997) or Hess (2001) for its intraday price impact.

${ }^{16}$ See, for example Rogers (1998, ch. 1).
} 
consensus forecasts of these figures which allow to measure the non-anticipated part of information arrival. ${ }^{17}$ Previous studies of the employment report restrict their attention to two headline figures, the nonfarm payroll measure and the unemployment rate. ${ }^{18}$ In addition to these, we use a third headline figure, i.e. average hourly earnings. ${ }^{19}$

Payroll employment and the (un)employment rate are strongly related, since both convey information about overall economic activity, consumers' spending power, as well as price pressures arising from the labor market. Therefore, it may be argued that using one of these figures is enough to capture most of the information. However, it is important to note that they are derived from different sources. While the (un)employment rate is derived from the household survey, the payroll measure (like hourly earnings) is based on the much larger establishment survey. ${ }^{20}$ Hence, in the short run they can move into opposite directions. Although it is often argued that market participants consider the nonfarm payroll figure to be more important, since changes in nonfarm payrolls are less volatile than changes in unemployment rates ${ }^{21}$ inspecting both figures might allow market participants to better assess the probability of measurement errors.

As mentioned above, financial markets also try to infer from employment figures whether inflationary pressures are building up which may arise from an increased bargaining power

\footnotetext{
${ }^{17}$ Analysts' forecasts of macroeconomic figures are not always unbiased and efficient (see e.g. Becker, Finnerty, and Kopecky 1996). However, there seems to be no systematic inefficiencies across different sample periods (see e.g. Hess and Moersch 2001).

${ }^{18}$ For example, Hardouvelis (1988), Dwyer and Hafer (1989) and Prag (1994) analyze surprises in unemployment rates, Fleming and Remolona (1997) use nonfarm payrolls, and Cook and Korn (1991), Edison (1996), Balduzzi, Elton, and Green (1997), and Hess (2001) use both headlines.

${ }^{19} \mathrm{~A}$ fourth headline figure, the average workweek, receives attention from time to time. This measure is not employed here since MMS does not provide survey data for this figure until October 1998. Hence, only a few data points are available.

${ }^{20}$ Based on interviews conducted with approximately 50.000 households, the (un)employment rate measures civilian noninstitutional employees including agricultural workers as well as self-employed persons. In contrast, the nonfarm payrolls figure draws from the payroll records of approximately 390.000 establishments and counts jobs added in nonagricultural industries. See, for example, Rogers (1998) ch. 1, or Niemira and Zukowski (1998) ch. 10.

${ }^{21}$ In fact, during our sample period the standard deviation of relative month-over-month changes in nonfarm payrolls turns out to be $0.119 \%$, in unemployment rates $0.161 \%$, and in hourly earnings $0.244 \%$. See also Hess and Moersch (2001).
} 
of employees in a tight labor market. Related but more direct information is obtained from average hourly earnings. Obviously, this figure provides a straightforward reading of price changes in the input factor labor. However, while hourly earnings primarily measure current price pressures, trends in employment may allow market participants to foresee wage increases down the road. Hence, hourly earnings add to the picture of price trends sketched by payrolls and unemployment rates by providing a look back.

Due to the differences in the information content of headline figures described above, one would expect that surprises in any of these three headline figures contribute to the explanation of returns observed after an announcement. This is stated by hypothesis H1.

\section{H1: Informativeness of headline figures}

After an announcement, prices react significantly to non-anticipated information in headline figures. Since all three headline figures are informative, they contribute to the explanation of returns.

\subsection{Efficient processing of non-anticipated information}

According to the well-known efficient market hypothesis one would expect that prices adjust immediately to public news arrival if this information is regarded to be important. However, only non-anticipated information can move prices, because in an efficient market prices already reflect widely anticipated events. The unique dissemination procedure of statistical agencies in the US guarantees that macroeconomic reports are released precisely according to the schedule. ${ }^{22}$ Reporters are allowed to analyze the data in advance but they are not allowed to communicate until the official release time. When the phone lines are turned on exactly at 8:30 a.m., headline figures are transmitted almost immediately to traders on the floor as well as to other market participants via news agencies. Thus,

\footnotetext{
${ }^{22}$ See, for example, Ederington and Lee $(1993,1995)$ or Fleming and Remolona (1997, 1999a) for a detailed description of these procedures.
} 
the most obvious non-anticipated information, i.e. surprises in headline figures should be incorporated into prices within a few minutes (hypothesis H2). The time span until this information is fully incorporated into prices may serve as a measure of market efficiency in terms of the speed of information diffusion.

\section{H2: Immediate price impact of headline information}

In an efficient market prices adjust immediately to non-anticipated information in the widely awaited headline figures. Thus no systematic impact is found after a few minutes.

Hypotheses H1 and H2 refer to the impact of information arrival on the mean function of the return process. The following section deals with the implications for the volatility process.

\subsection{The volatility impact of information arrival}

The sharply increased volatility immediately after macroeconomic announcements as well as its persistence is well documented (see e.g. Ederington and Lee 1993, Crain and Lee 1995, Fleming and Remolona 1997, 1999a and Franke and Hess 2000a). In order to delineate the impact of macroeconomic announcements on volatility, we differentiate between four components: (1) the impact of the mere existence of new information, i.e. the baseline volatility time pattern related to the announcement of the employment report, (2) the magnitude of non-anticipated information in this report, i.e. absolute surprises in headline figures, (3) the asymmetric impact of good and bad news on volatility, i.e. signed surprises, and (4) the 'reinforcement' effect of surprises in related headline figures, i.e. whether surprises in newly created jobs (payrolls) and the overall (un)employment rate convey the same message. 
The first component captures a volatility increase due to an acceleration of the speed of information diffusion after an announcement. This component accounts for the well-known effect that information arrival is associated with higher trading volume as well as higher volatility (for a comprehensive overview see e.g. Karpoff 1987 or Goodhart and O'Hara 1997). Note that this component does not account for specific details concerning the type of information, the magnitude, or the direction of surprises. Hence, it captures the deterministic time pattern of volatility around announcements as a baseline. One argument for a persistently higher volatility after announcements stems from the mixture of distribution hypothesis (Clark 1973, Harris 1987), stating that both volume and volatility are driven by the rate of information arrival. Clusters in news then lead to a positively autocorrelated volatility. Considering that an employment report contains a load of detail information besides the exposed headline figures and assuming that this information is only gradually processed, the mixture of distribution hypothesis provides one explanation for volatility clustering after such a report. A somewhat related argument is provided by the sequential information arrival model (Copeland 1976, 1987), which assumes that not all market participants receive the information at the same time. ${ }^{23}$ Another argument is that even if market participants have the same access to the information at the same time, differences of opinion about its price impact can persist for quite some time (e.g. Varian 1985, Kandel and Pearson 1995, or Harris and Raviv 1993). Market participants may interpret the data differently, either if they have additional private information, different prior beliefs, or if they use different models to evaluate the impact of news. Hypothesis H3 summarizes these arguments:

\section{H3: Baseline volatility after an announcement}

Volatility increases after an employment release and declines only slowly due to (1)

\footnotetext{
${ }^{23}$ This view is supported for example by Dacorogna, Müller, Nagler, Olsen, and Pictet (1993) and Müller, Dacorogna, Davé, Olsen, Pictet, and von Weizsäcker (1997), who argue that different market participants have different time horizons to process information and to act upon it. This leads to waves in trading activity and thus to waves in price volatility.
} 
the huge amount of detail information contained in this report, (2) traders' different response horizons, and/or (3) differences of opinion about the precise price impact of new information.

The effect of an awaited employment announcement on the volatility before this event is less clear. On the one hand there is some evidence that trading volume declines before such an announcement. ${ }^{24}$ Then, the well-documented positive volume-volatility relation (see e.g. Karpoff 1987) would suggest that volatility before an announcement is lower. However, a possible counterargument arises from the liquidity of markets. If speculative trading dries out, liquidity trades may have a higher price impact. This would increase volatility before an announcement. ${ }^{25}$ Hypothesis $\mathrm{H} 4$ follows the first line of reasoning suggesting a "calm before the storm" effect.

\section{H4: Baseline volatility before an announcement}

Volatility is depressed before an announcement.

The second component in the variance specification accounts for the magnitude of nonanticipated information in a report, measured by the deviation of announced headline figures from analysts' 'consensus' forecasts. It seems to be unclear why large surprises should lead to higher volatility, especially if one controls for the direct impact of surprises on the mean function. Since these surprises have a high visibility, i.e. market participants get the information very fast via news vendors such as Bloomberg or Reuters, one would expect an immediate and consistent price reaction rather than a prolonged stage of random fluctuations. One explanation for a persistently high volatility could be that a surprise in a

\footnotetext{
${ }^{24}$ Fleming and Remolona (1999a), for example, report that trading volume in U.S. Treasuries is slightly but insignificantly lower before an announcement. Franke and Hess (2000a) find that Bund future trading volume is significantly lower in the 5-minute interval preceding 8:30 announcements and insignificantly lower before releases scheduled at 9:15 and 10:00 ET.

${ }^{25}$ See, for example, Franke and Hess (2000a).
} 
headline figure increases the probability that there are also surprises in other less exposed figures and that it is not easy for market participants to find out what else might be affected. Therefore, market participants may have more difficulties in assessing the precise price impact of larger surprises. In addition, surprises leave more room for differences of opinion if one considers the possibility of imprecise measurements. For example, it may be unclear whether a surprise is due to a measurement error, i.e. market participants may disagree about the precision of the signal. Extreme surprises may even call the reliability of forecast models in question. This is stated by hypothesis H5.

\section{H5: Volatility impact of the magnitude of surprises}

Larger surprises give rise to more pronounced differences of opinion. Hence, volatility increases with the magnitude of surprises.

The third volatility component allows us to investigate whether 'good' and 'bad' news have a different impact on volatility (hypothesis H6). An asymmetric volatility response coupled with an asymmetric mean response may be interpreted as evidence in favor of the time-varying risk premium hypothesis (see e.g. Pindyck 1984 and French, Schwert, and Stambaugh 1987). If risk is priced and traders anticipate that negative news will produce a stronger increase in volatility, a higher required rate of return leads to a stronger decline in prices. While this effect has been studied in particular for stock markets, it should be observed for bond prices too. ${ }^{26}$ On the basis of daily data, Li and Engle (1998), for example, report strong asymmetric effects of scheduled announcements on the T-bond future. They find that positive shocks depress volatility on consecutive days and vice versa. While Li and Engle define 'good' and 'bad' news on the basis of the observed daily return reactions, we directly exploit the sign of analysts' forecast errors in the headline

\footnotetext{
${ }^{26}$ Although obviously not applicable to bonds, there is a second explanation for the asymmetric volatility response in the stock market which draws on the leverage effect (see e.g. Black 1976 and Christie 1982). A drop in stock prices causes an increase of the market price of debt relative to the market price of equity. This increase in the financial leverage makes the stock riskier, and thus increases its volatility.
} 
figures to assess whether a surprise provides 'good' or 'bad' news. ${ }^{27}$ This allows us to investigate asymmetric effects for each of the headline figures separately.

\section{H6: Asymmetric volatility impact of surprises}

Traders' uncertainty, and thus volatility, is higher for 'bad' news than for 'good' news.

The fourth volatility component is included in order to investigate a possible interaction between surprises in headline figures in more detail. Recall that both the nonfarm payrolls figure and the (un)employment rate may indicate future price pressures arising from a tight labor market. Since these two figures are closely related, market participants can use them to cross-validate each other. If both headline figures convey the same message, e.g. a surprisingly high increase in nonfarm payrolls and a lower than expected unemployment rate, the room for differences of opinion about a tight labor market is reduced. A large surprise in one headline figure might be interpreted as a measurement error. If large surprises in both figures occur which point in the same direction, then the possibility of a measurement error is reduced. In this case, one would expect a sharp initial price reaction, but on the other hand volatility afterwards should be comparatively low. In other words, we should observe a more moderate increase in volatility if large surprises in nonfarm payrolls and the unemployment rate cross-validate each other. ${ }^{28}$ Hence, the fourth component examines whether multiple surprises pointing in the same direction reduce the room for differences of opinion (hypothesis H7).

\section{H7: Reinforcement effect of surprises in related figures}

\footnotetext{
${ }^{27} \mathrm{Li}$ and Engle (1998) define, for example, 'big negative news' as news corresponding with (daily) returns lower than $33 \%$ quantile. In contrast, here, 'bad' news is given by a higher than expected nonfarm payrolls figure $\left(S 1^{+}\right)$, a lower than predicted unemployment rate $\left(S 2^{-}\right)$, and a higher than forecasted average hourly earnings announcement $\left(S 3^{+}\right)$.

${ }^{28}$ A 'large' surprise will be defined as a surprise exceeding one standard deviation.
} 
Volatility is lower if large surprises in the related nonfarm payrolls figure and the unemployment rate mutually confirm their messages, i.e. if both provide either 'good' or 'bad' news, since then less room is left for differences of opinion. Moreover, this effect is more pronounced for negative surprises given the existence of asymmetric effects (H6).

\section{Empirical analysis}

\subsection{Data}

We analyze Chicago Board of Trade (CBOT) T-bond futures returns in 2-minute intervals during 90-minute windows around employment releases, more precisely from 8:22 to 9:52 a.m. ET (Eastern time). This window is suggested on the one hand by the floor trading hours of the CBOT which start at 8:20 a.m., ${ }^{29}$ and on the other hand by the release of other macroeconomic announcements at 10:00 a.m. Log returns are calculated on the basis of the last trading price observed in a given 2-minute interval. For example, the return associated with the employment release, i.e. the 8:30-8:32 return, is computed from the last price before the 8:30 announcement and the last price before 8:32. Since the employment report is released almost always on Fridays, we do not have to account for day-of-the-week effects. ${ }^{30}$ We only use those days on which no other macroeconomic report is released during the 90-minute period. Using a five-year sample, i.e. January 1995 to December 1999, we obtain 53 announcement days. ${ }^{31}$ CBOT T-Bond futures data are obtained from the Futures Industry Institute. These are 'tick-by-tick' data containing a time-stamped

\footnotetext{
${ }^{29}$ The definition of 2-minute returns does not allow to calculate a return for the 8:20-8:22 interval since no price is observed before 8:20.

${ }^{30}$ Typically, the employment report is released on the first Friday after the end of the month it refers to. During the sample period 3 reports were announced on a Thursday since the first Friday was a holiday. Moreover, after controlling for the impact of announcements, Li and Engle (1998) do not find a significant difference between Thursdays and Fridays. This is in line with the findings of Ederington and Lee (1993), Franke and Hess (2000a), and others suggesting that most of the day-of-week and time-of-the-day effects in bond markets can be explained by the announcement schedule.

${ }^{31} 7$ days are removed at which either leading indicators, personal income, or gross domestic product were released at the same time.
} 
record whenever a price change is observed. Transaction volumes are not recorded. Like in previous studies, the front month contract is analyzed, i.e. the most actively traded contract among the nearby and second nearby contract. ${ }^{32}$ As an illustration for the impact of announcements, the $1 \%$ and $99 \%$ as well as the $5 \%$ and $95 \%$ fractiles of 2 -minute $\log$ returns are shown in figure 1.

\section{[insert figure 1 around here]}

To explore the effect of the bid-ask bounce on the results, some experiments are conducted using log returns computed on the basis of so-called 'pseudo equilibrium prices' as suggested by Ederington and Lee (1995). These are obtained as the average of the last two prices in an interval. However, the results do not change in any meaningful aspect using 'pseudo equilibrium prices'. Neither coefficients in the mean nor in the variance function are affected substantially. Although this is somewhat in contrast to the results reported by Ederington and Lee (1995), it is not surprising since a higher aggregation level is used. The influence of the bid-ask spread on returns in very narrow 10-second intervals is much more pronounced since price changes are much smaller as compared to 2-minute intervals. ${ }^{33} \mathrm{In}$ addition, there seems to be a trade-off between the bias induced by the bid-ask spread and the bias induced by averaging over lagged prices especially during periods of dense information arrival.

Non-anticipated information is measured on the basis of survey data on analysts' forecasts provided by Standard \& Poors Global Markets (MMS). Initially released non-revised figures were extracted from the original monthly releases. Surprises are defined as the difference between initially announced figures and the median of analysts' forecasts. To facilitate

\footnotetext{
${ }^{32}$ See, for example, Ederington and Lee (1995) or Franke and Hess (2000a).

${ }^{33}$ The impact of the bid-ask spread depends on the size of the bid-ask bounce relative to average (absolute) price changes in a given interval. In an extremely liquid market, like the T-Bond futures market, 2-minute intervals seem to be enough to eliminate the influence of the bid-ask spread largely.
} 
a comparison between the headline figures, standardized surprises are used, i.e. for each headline surprises are divided by the sample standard deviation of surprises.

\subsection{Specification of the mean function}

In this subsection we focus on the mean function of the return process and estimate eq. (3) without already specifying the (conditional) variance $h_{t}$ (eq. 4 ). Here it is assumed to be time-invariant, i.e. $h_{t}=h .{ }^{34}$ With $r_{t}$ denoting 2 -minute log returns $(\times 10,000)$ we estimate

$$
r_{t}-\mathrm{E}\left[r_{t}\right]=\sqrt{h} \cdot u_{t}, \quad \text { where } \quad \mathrm{E}\left[r_{t}\right]=x_{t}^{\prime} \beta
$$

The response of the price process to non-anticipated information is analyzed based on the explanatory variables $x$ which capture surprises in headline figures (see section 2). Surprises in nonfarm payrolls, unemployment rates, and hourly earnings are denoted by $S 1, S 2$, and $S 3$, respectively. In addition, time dummies are defined which take on the value 1 for a given interval and zero else, i.e.

$$
D_{\tau}= \begin{cases}1 & \text { if } t=\tau \\ 0 & \text { else }\end{cases}
$$

where $t=1, \ldots, 45$ denotes the 2-minute intervals between 8:22 a.m. and 9:52 a.m. Moreover, surprise dummies are defined for each 2-minute time interval such that the surprise variables interact multiplicatively with the dummy variables, i.e.

$$
S_{\tau}=D_{\tau} S, \quad \text { with } S \in\{S 1, S 2, S 3\}
$$

For example, the interaction term $S 2_{8: 32-8: 34}=D_{8: 32-8: 34} \times S 2$ captures the impact of a surprise in headline 2 on the return in the interval 8:32-8:34. In addition, lagged 2-minute log returns are included in the regressions.

\footnotetext{
${ }^{34}$ This requires to use heteroskedasticity robust inference techniques.
} 
In a first step, we analyze the impact of the different types of information separately by running simple OLS regressions of 2-minute log returns on different sets of the corresponding surprise variables. In all regressions the above defined dummy variables cover the interval from 8:28 a.m. to 8:36 a.m. ${ }^{35}$

[insert table 1 around here]

As a benchmark, the first regression, i.e. specification (1) in table 1, includes only a constant and lagged returns. In addition, the second regression (spec. 2) includes variables capturing detailed information concerning the first headline figure, i.e. nonfarm payrolls $(S 1)$. The following findings can be summarized:

First, the estimated coefficients provide evidence for a significant impact of the surprise on the price, i.e. the higher the difference between the announced number and the corresponding forecast, the stronger the resulting decline of the price. ${ }^{36}$ The strikingly high coefficient of the 8:30-8:32 surprise dummy $\left(S 1_{8: 30-8: 32}\right)$ supports hypothesis H1 which says that the arrival of non-anticipated information causes sharp price reactions.

Second, the significant coefficients of the absolute nonfarm payrolls surprise dummies (in particular $\left|S 1_{8: 32-8: 34}\right|$ ) suggest an asymmetric response to 'good' and 'bad' news. The asymmetry in the response to surprises is particularly pronounced in the second interval ${ }^{37}$ : 'Bad' news still have quite a negative impact on returns in the 8:32-8:34 interval, while 'good' news of the same size have almost no impact. ${ }^{38}$ Note, however, that a significant

\footnotetext{
${ }^{35}$ We also included dummies capturing further intervals before and after the announcement but did not find any significant impacts.

${ }^{36}$ Note that a higher than expected outcome of nonfarm payrolls as well as of hourly earnings is 'bad news' and should lead to an increase in interest rates and a decline in T-bond futures prices. In contrast, a lower than expected unemployment rate is also considered to be 'bad news' for T-bond futures.

${ }^{37}$ The asymmetric response in the 8:30-8:32 interval is only slightly significant in specification (2). It becomes insignificant when the other headline figures are included (see spec. 5, table 1).

${ }^{38}$ For example, a surprise of plus one standard deviation $\left(S 1_{8: 32-8: 34}=\left|S 1_{8: 32-8: 34}\right|=+1\right)$ lowers returns in the 8:32-8:34 interval by around $0.15 \%$, i.e. $(-7.577-7.093) / 10000$. In contrast, a surprise of minus one standard deviation $\left(S 1_{8: 32-8: 34}=-1\right.$ and $\left.\left|S 1_{8: 32-8: 34}\right|=+1\right)$ increases returns only slightly, i.e. $(+7.577-7.093) / 10000$.
} 
asymmetric response is found only for the nonfarm payrolls figure, but not for the other headline figures.

Third, focusing on the time pattern of the price response induced by the payrolls surprise, we find significant price movements between two minutes before $\left(S 1_{8: 28-8: 30}\right)$ and four minutes after the announcement $\left(S 1_{8: 30-8: 32}\right.$ and $S 1_{8: 32-8: 34}$ as well as $\left|S 1_{8: 30-8: 32}\right|$ and $\left.\left|S 1_{8: 32-8: 34}\right|\right)$. The significant price reaction in the 8:28 to 8:30 interval provides some evidence for slight leakage effects. This result is quite surprising, since in the US strict lock-up conditions should rule out any leakage of information. ${ }^{39}$ However, the largest price reaction is observed within the 8:30-8:32 interval. This reaction sharply declines between 8:32-8:34 and disappears within the following 2-minute interval. These results indicate that the T-bond futures market rapidly advances towards a new equilibrium level after the arrival of non-anticipated information. Thus, the finding of a fast information diffusion strongly supports hypothesis H2.

The analysis described above is repeated for the remaining two headline figures, i.e. the unemployment rate $S 2$ and hourly earnings $S 3$. Regression results are given in columns (3) and (4) of table 1. Again, surprises in these headline figures cause strong price responses within the 8:30-8:32 interval coinciding with the announcement.

Since after 8:32 no statistically significant influence is found, non-anticipated information associated with the unemployment rate and hourly earnings seems to be processed even more rapidly. The adjustment is basically completed within two minutes after the release. Moreover, note that the signs of the estimated coefficients for signed surprise dummies $\left(S 2_{8: 30-8: 32}, S 3_{8: 30-8: 32}\right)$ support the hypothesized price reactions. T-bond futures prices rise in response to 'good' news from the inflation front, i.e. a lower than expected increase in nonfarm payrolls, a higher than expected unemployment rate, and a lower than expected average hourly earnings figure. In contrast to the nonfarm payrolls, there is no indication

\footnotetext{
${ }^{39}$ However, note that if we model the mean and the variance simultaneously, the significance of this effect is reduced. See the results provided in the following section.
} 
of an asymmetric response to surprises in these figures since the $\mid S 2$.| and $\mid S 3$.| coefficients are insignificant. ${ }^{40}$

In regressions (5) and (6), the joint impact of the different types of non-anticipated information is evaluated. A very important result is that the estimated coefficients remain relatively stable when the corresponding explanatory variables, associated with surprises in the other headline figures, are included. In general, the significance of the variables is nearly unchanged which illustrates the robustness of the results. These findings indicate that each of the different types of non-anticipated information contributes to the explanation of the return process which provides strong evidence in favor of hypothesis H1. Thus, market participants do not only assign weight to nonfarm payrolls but also pay attention to unemployment rates and hourly earnings.

In order to achieve a more parsimonious representation of the mean function, in regression (6) only those surprise variables are included which turned out to be significant in the previous regressions, i.e. (1) to (5). Note that no substantial change in the estimated coefficients is recorded, besides for the insignificant $\left|S 1_{8: 30-8: 32}\right|$ variable.

The analysis of the explanatory power of the particular models based on the adjusted coefficient of explained variation $\bar{R}^{2}$ yields some interesting insights: First, accounting for autocorrelation in returns without including surprise variables (column 1) explains virtually nothing $\left(\bar{R}^{2}=0.1 \%\right)$. Second, including surprise variables associated only with one of the headline figures results in a substantial increase of the explanatory power (nonfarm payrolls $+18.0 \%$, unemployment rates $+13.5 \%$, and hourly earnings $+5.7 \%) .{ }^{41}$

\footnotetext{
${ }^{40}$ In contrast to $\mathrm{S} 1$, for which signed and absolute surprises are virtually uncorrelated $(\operatorname{corr}(S 1,|S 1|)=$ $0.04)$, the correlation of $S 2$ and $|S 2|$ is -0.37 and that of $S 3$ and $|S 3|$ is 0.46 . Hence, including both signed and absolute variables causes multi-collinearity effects. This becomes evident by the changes of the coefficient signs of the insignificant $|S 2|$ and $|S 3|$ variables (compare columns (3) and (5), and (4) and (5), respectively).

${ }^{41}$ While the employment release is often referred to as 'the king of announcements' (See, for example, Li and Engle 1998, or Andersen and Bollerslev 1998), the results of these regressions suggest that the nonfarm payroll component 'wields the scepter'. Nevertheless, the regularly neglected hourly earnings figure still has some explanatory power.
} 
Third, including all three headline figures (model 5), explains $32.4 \%$ of the total variation which is a quite satisfying result for an intraday return process. The strongly reduced model, which includes only the significant variables (column 6 ), explains $31.2 \%$ of the variation.

\subsection{Specification of the variance function}

Besides the analysis of the price impact, a further major issue in this paper is the investigation of the variance impact of the arrival of non-anticipated information. To analyze the time pattern of the volatility response, we use an ARCH specification with multiplicative heteroskedasticity. While in the previous section the variance $h_{t}$ was assumed to be time-invariant, now it is modelled as (eq. 4)

$$
h_{t}=\sigma_{t}^{2}+s_{t}^{2}=\phi \epsilon_{t-1}^{2}+\exp \left(w_{t}^{\prime} \gamma\right)
$$

where $w_{t}$ is a vector of explanatory variables consisting of the surprise variables and time dummies entering the variance specification collectively as multiplicative heteroskedasticity. $w_{t}$ includes a constant term which can be interpreted as a baseline volatility level. $\gamma$ is the corresponding coefficient vector.

As discussed in section 2, we neglect any daily GARCH components since we focus on 90-minute windows around announcements of the employment report which is released on a monthly schedule. Moreover, we are primarily interested in the variance response due to surprise effects and not in the volatility persistence. Therefore, only three ARCH terms are included. ${ }^{42}$ This seems to be appropriate to capture the variance dynamics within the particular 90-minute windows. However, since we neglect a possible volatility component, we use a robust inference based on pseudo ML estimates of the variance-covariance matrix (see Bollerslev and Wooldridge 1992).

\footnotetext{
${ }^{42}$ Note that the implementation of a GARCH effect would lead to an inclusion of the explanatory variables in the model dynamics which would complicate the interpretation of the results.
} 
The mean function is modelled based on the specification of column (6) in table 1 . The estimation results for the complete model are given in table 2.

[insert table 2 around here]

As a starting point, a simple $\mathrm{ARCH}(3)$ specification is given in column (1) of table 2 . It illustrates the existence of a significant first order serial dependence in the variance function with an $\mathrm{ARCH}$ coefficient of 0.521 . Note that for all models the significance of the $\operatorname{ARCH}(2)$ coefficients is substantially lower and the $\mathrm{ARCH}(3)$ term is insignificant.

Columns (2) to (6) show the results of ARCH models with multiplicative heteroskedasticity. The model given in column (2) accounts for the deterministic pattern of volatility by including a set of time dummies covering the period from 8:26 a.m. to 9:40 a.m. ${ }^{43}$ The variance peaks out in the interval just after the announcement (8:30-8:32) and declines almost monotonically until about one hour after the event. After this period, we do not find significant differences compared to the volatility level of the base category. Since the explanatory variables enter the variance equation exponentially, at its peak between 8:30 and 8:32, the conditional variance is more than 50 times higher than the variance in the base period, while it drops to a factor of around 9 in the following interval. 30 minutes after the announcement, the conditional variance is just about twice as high as in the base period. Thus, we find an extreme volatility response immediately after the announcement, followed by a relatively strong decline within the first minutes and a more slowly decaying structure a longer time after the news arrival. Hence, these findings strongly support hypothesis H3.

Furthermore, some empirical evidence is obtained indicating that volatility starts to rise between 8:26 to 8:28 and shows a strong increase just before the announcement. Therefore,

\footnotetext{
${ }^{43}$ The base category is the time before the announcement $(8: 22-8: 26)$ and the last 12 minutes of the analyzed time interval (9:40-9:52). This categorization is quite reasonable as it allows us to analyze the variance response due to announcement effects compared with the variance level before and a longer time after the announcement.
} 
hypothesis $\mathrm{H} 4$ is clearly rejected. The detection of a pre-announcement surge in volatility is in line with the results of Ederington and Lee (1995), Fleming and Remolona (1999a), Franke and Hess (2000a), and others.

A further important finding is a significant decrease of the ARCH coefficients compared to specification (1) which indicates that the volatility response due to the arrival of nonanticipated information seems to be a major source of autocorrelation in the volatility process.

In regressions (3) and (4), both variables accounting for the deterministic time pattern and the surprise variables are included. Note that these variables enter the variance specification multiplicatively, i.e. the surprise variables interact with the complete set of time dummies, leading to proportional downward or upward shifts of the variance function. In column (3), variables capturing the magnitude of surprises in the three headline figures are added, i.e. absolute surprises $(|S 1|,|S 2|$, and $|S 3|)$. We find significantly positive coefficients, thus large surprises lead to higher variances which supports hypothesis H5. Column (4) allows to investigate asymmetric effects by adding signed surprises $(S 1, S 2$, and S3). The results suggest a significant positive impact of 'bad' news for $S 1$ and $S 3$ which confirms hypothesis H6. ${ }^{44}$ No significant asymmetric influence is found for $S 2$.

The model in column (5) includes both signed as well as absolute surprise variables. Note that the coefficients and corresponding standard errors remain quite stable, indicating the robustness of the results. This confirms the preliminary results of model (3) and (4). Hence, we obtain empirical evidence for the existence of absolute effects (H5) and asymmetric effects (H6) of surprises in nonfarm payrolls and hourly earnings. ${ }^{45}$

Finally, model (6) includes two interaction terms between surprises in nonfarm payrolls

\footnotetext{
${ }^{44}$ Recall that positive surprises in $S 1$ and $S 3$ cause negative price movements. In contrast, negative price movements are caused by negative surprises in $S 2$.

${ }^{45}$ Similar asymmetric effects associated with scheduled announcements have also been found by $\mathrm{Li}$ and Engle (1998) based on daily data. However, Li and Engle define 'negative' news indirectly on the basis of the observed price reaction rather than including the signed surprise.
} 
and unemployment rates in order to test for the reinforcement effect stated by hypothesis H7. $I^{S 1^{++} S 2^{--}}$takes on the value one if a large ${ }^{46}$ positive value for $S 1$ and at the same time a large negative value for $S 2$ is observed and zero else. This dummy variable is interacted with the time dummies, creating a separate variable for the interval from 8:30 to 8:38 in which volatility is extremely high, i.e. $I_{8: 30-8: 38}^{S 1^{++}}$, and another variable for the subsequent phase of rather moderately increased volatility, i.e. $I_{8: 38-9: 20}^{S 1^{++}} 2^{--}$. As hypothesized by H7, a strong and highly significant reduction of volatility is found if both headline figures convey extremely bad news and thus mutually reconfirm their messages. ${ }^{47}$ This indicates that the room for differences of opinion is significantly reduced if reconfirmation of bad news reduces the possibility of a measurement errors. Then volatility is substantially decreased.

Analyzing the goodness-of-fit of the particular specifications based on the Bayes Information Criterion (BIC) reveals that the inclusion of time dummies leads to the strongest improvement. This result illustrates the importance of accounting for the time pattern of the volatility response due to announcement effects. Further improvements of the model are reached by the inclusion of the particular surprise variables. The lowest BIC value is obtained based on specification (5).

In order to evaluate the goodness-of-fit of the different volatility specifications based on insample predictions, we follow Pagan and Schwert (1990) and regress the 2-minute squared residuals $\hat{\epsilon}_{t}^{2}$ on the corresponding variance forecasts $\hat{h}_{t}$ based on the individual specifications $(1$ to 6$)$, i.e. $\hat{\epsilon}_{t}^{2}=a_{0}+a_{1} \hat{h}_{t}+\nu_{t}$. Then, the goodness-of-fit is evaluated based on the coefficient of explained variation $R^{2}$ associated with this regression as well as on the estimates $\hat{a}_{0}$ and $\hat{a}_{1} .{ }^{48}$ Results of this estimation are given in the last four lines of table 2. They show that the predictive performance increases substantially when explanatory variables capturing the volatility response due to the announcement schedule are included.

\footnotetext{
${ }^{46}$ Here, large is defined as exceeding one standard deviation.

${ }^{47} \mathrm{We}$ also analyzed positive reinforcement effects, i.e. extremely 'good' news in the two headline figures, but these did not turn out to be significant.

${ }^{48}$ Note that unbiased predictions imply values of $a_{0}=0$ and $a_{1}=1$.
} 
This confirms the findings based on the BIC. Again, the goodness-of-fit is only slightly improved when the particular surprise variables are taken into account. For the complete model, i.e. specification (6), the highest $R^{2}$ is obtained (0.287) corresponding to a correlation between squared residuals and variance predictions of $\operatorname{Corr}\left(\hat{\epsilon}_{t}^{2}, \hat{h}_{t}\right)=0.536$. However, the fact that the estimated slope coefficient $a_{1}$ is significantly larger than 1 indicates that specification (6) yields slightly biased predictions. Moreover, we obtain a higher BIC value than for specification (5). Hence, highly significant coefficient estimates indicate the existence of reinforcement effects, whereas the BIC criterion and the in-sample forecast tests suggest that the overall model performance is not increased.

\section{Stability of the results - A look at other announcements}

To complete our analysis and to provide a simple robustness test, we analyze the processing of non-anticipated information contained in three other, quite different macroeconomic releases: the report of the National Association of Purchasing Managers (NAPM), consumer prices (CPI), and housing starts (HS). ${ }^{49}$ Analysts' forecasts are available for one headline figure of the NAPM report (i.e. the overall index) and the HS report (i.e. the total number of residential construction starts) and for two headline figures of the CPI report (i.e. the overall CPI and the core CPI which excludes volatile food and energy prices). Although two CPI headlines are available, in contrast to the employment report's unemployment and payroll figures, the CPI figures do not originate from different surveys. Since the core CPI only removes some prices from the overall CPI's basket, a considerable overlap remains in what is measured by the two figures. Consequently, a high correlation

\footnotetext{
${ }^{49}$ The NAPM index provides even more timely information about economic activity than the employment report since it is typically released a few days earlier. In contrast, the BLS's CPI report is announced around one week later, and another week later, the Commerce Department's housing start figures. While the NAPM index and housing starts allow market participants to gauge the strength of economic activity, and hence possible inflation pressures, the CPI report provides a direct reading of price changes. For more details see, for example, Rogers (1998).
} 
coefficient between surprises in the total CPI and the core CPI is found, i.e. $0.61 .^{50}$ This leads to multi-collinearity problems, especially if we include both signed and absolute surprise variables into our analysis. Besides the high correlation, the fact that the CPI figures are not based on different surveys, and hence, do not allow traders to gain much evidence about the occurrence of measurement errors, precludes an analysis of the reinforcement effect. Therefore, we perform the analysis for each headline figure separately. Nevertheless, we are able to check the robustness of the remaining results reported in the previous section.

Again, we measure surprises as deviations from MMS forecasts and apply a 90-minute window around the release of each report. ${ }^{51}$ Analyzing unique announcements, we exclude those days on which other reports are announced in this interval. While the overlap with other announcements is minimal for the employment report, we loose considerably more observations for the other three announcements, in particular for the NAPM and CPI report (see table 3 ).

\section{[insert table 3 around here]}

Estimation results for the simultaneous mean and variance impact of the individual headline figures are given in table 3. First, focussing on the mean function the following results can be summarized: Again, non-anticipated information is processed rather rapidly. ${ }^{52}$ With the exception of the NAPM index, the highest impact is found in the announcement interval $\left(S 1_{8: 30-8: 32}\right)$. Nevertheless, the magnitude of this impact is considerably lower as

\footnotetext{
${ }^{50}$ This is due to the fact that announced changes in the total and core CPI figures are highly correlated, i.e. 0.55. In contrast, announced changes in unemployment rates and nonfarm payrolls are almost uncorrelated, i.e. -0.18 .

${ }^{51}$ Surprises are standardized by their sample standard deviation. For the NAPM report which is released at 10:00 ET we use the window from 9:52 to 11:22. Since the other reports are announced at 8:30 ET, we apply the same window as for the employment report, i.e. 8:22-9:52.

${ }^{52}$ The signs of the estimated surprise variables are in accordance with standard theory: A higher than expected NAPM or HS reading indicates higher economic activity which might lead to a higher expected real interest rates and/or to higher expected inflation rates. CPI figures provide a direct measure of (past) inflation rates. Hence, surprises in the four headline figures should have a negative impact on T-bond futures returns.
} 
compared to the employment report. There seems to be some lagged response to the NAPM release (but also a leakage effect) which may be due to a less strict announcement procedure of this non-government report. However, for the other reports the processing of non-anticipated information is completed within the first two minutes after the announcements. Moreover, similar to the nonfarm payrolls figure, indications of an asymmetric mean response are found for all the four headline figures. Overall, a similar reaction of the conditional mean function of the return process to non-anticipated information in these figures is observed, although the reaction to employment figures is much more pronounced. Nevertheless, this finding strongly confirms the above reported results with respect to the mean impact.

In addition, the impact of the four figures on the variance process also resembles the variance impact of the employment headlines. Again, only small but mostly highly significant $\operatorname{ARCH}(1)$ coefficients are found, while only one $\mathrm{ARCH}(2)$ and no $\mathrm{ARCH}(3)$ term is significant when surprise variables are included into the specification. Moreover, the estimated deterministic volatility pattern is quite similar. It shows a strong increase of volatility after the announcement, followed by a rapid decline to the base level. However, the volatility peak is not quite as high (e.g. for NAPM 'only' 10 times higher than the base level) and volatility returns faster to the base level (within about 30 minutes). ${ }^{53}$ More importantly, the results concerning the impact of surprises on the volatility are strongly confirmed. For all the four figures we find a (highly) significant positive impact of absolute surprises. In addition, the estimated coefficients of the surprise variables are of comparable magnitudes, only absolute NAPM surprises seem to have a somewhat stronger impact. The results for the asymmetric volatility response are also confirmed: For all the four headline figures we find again that 'bad' news, i.e. positive surprises which have a negative impact on returns, raise the volatility.

\footnotetext{
${ }^{53}$ This is in line with the findings of Bollerslev, Cai, and Song (2000) that the deterministic volatility pattern around employment releases is higher and more persistent in comparison to other releases.
} 
Overall, these results suggest that the simultaneous mean and variance impact of nonanticipated information in the employment report is not a unique phenomenon. Nonanticipated information in widely awaited macroeconomic headline figures is incorporated very rapidly into T-bond future prices suggesting that traders' average beliefs about the new equilibrium price level shift almost instantaneously. But surprises also create uncertainty. Volatility is higher after large surprises, in particular after 'bad' news, indicating that traders' opinions about the precise price impact are more dispersed. Although these effects on first and second moments are quite similar across individual releases, the employment report is special in the sense that it allows market participants to cross-validate information provided by its headline figures. This is due to the fact that nonfarm payrolls and unemployment rates are derived from two independent surveys. Therefore, the employment report allows market participants a better assessment of the probability of measurement errors. In situations where measurement errors can be ruled out, less room for differences of opinion is left, and hence volatility is reduced.

\section{Conclusions}

This paper scrutinizes the processing of information contained in the U.S. employment report. The impact of non-anticipated information arrival on both first and second moments of the return process is analyzed. This allows some interesting insights into the creation of uncertainty by the release of macroeconomic news.

In contrast to the previous literature which investigates volatility while refraining from including variables into the mean function that account for surprises, we control for the consistent price reaction to non-anticipated information. With a completely specified mean function, the volatility function receives a different interpretation: Rather than capturing just the fluctuations of squared returns, the volatility function describes market participants' uncertainty about the precise price impact of new information, while the mean 
function describes the shift in average beliefs about the new equilibrium price level induced by the arrival of non-anticipated information.

The main results derived on the basis of this estimation approach are as follows. First, surprises in all three headline figures have a distinct impact on the level of prices, with the nonfarm payrolls figure having the strongest impact. Second, non-anticipated information leads to an almost instantaneous price reaction which is completed within the first two to four minutes. This indicates that the market advances very rapidly to a new equilibrium price level. Third, volatility is slightly higher before the announcement, which might be due to a temporary illiquidity before the announcement. Volatility surges immediately afterwards. In particular, volatility peaks out in the 2-minute interval associated with the announcement, and is substantially reduced in the following interval, though remaining elevated for about one hour. The high volatility after the announcement suggests that there is considerable uncertainty about the precise price impact of new information. Forth, strong magnitude effects of surprises are found to have an impact on volatility, i.e. larger surprises do not only lead to a more pronounced price reaction, they also create more uncertainty. Fifth, there are strong asymmetric effects, i.e. 'bad' news measured in terms of the surprises contained in headline figures raise the volatility substantially while 'good news' reduce traders' uncertainty. This suggests that market participants have more difficulties to assess the precise price impact of news when negative shocks occur. Last but not least, a strong interaction is detected between headline figures with a related information content. Pointing in the same direction, extremely bad news in the nonfarm payrolls figure reinforce the signal of a devastating unemployment rate reading. This cross-validation of extreme signals leaves less room for traders' differences of opinion, and hence decreases volatility.

Analyzing the stability of these results, similar effects are found for other scheduled announcements. This suggests some regularities in the processing of non-anticipated macroe- 
conomic information. However, the fact that the main employment headlines are derived from two independent surveys distinguishes the employment report to some extent from other releases. This dual-survey sampling allows market participants a more accurate assessment of the probability of measurement errors, and hence a more precise assessment of the price impact of the survey results. 


\section{References}

Almeida, A., C. A. E. Goodhart, and R. Payne (1998): "The effects of macroeconomic news on high frequency exchange rate behavior," Journal of Financial and Quantitative Analysis, 33, 383-408.

Andersen, T. G., and T. Bollerslev (1997): "Intraday periodicity and volatility persistence in financial markets," Journal of Empirical Finance, 4, 115-158.

(1998): "Deutsche Mark-Dollar volatility: intraday activity patterns, macroeconomic announcements and longer run dependencies.," Journal of Finance, 53, 219-265.

Balduzzi, P., E. J. Elton, and C. Green (1997): "Economic news and the yield curve: Evidence for the U.S. Treasury market," Discussion paper, New York University, Oktober 1997.

Becker, K. G., J. E. Finnerty, and K. J. Kopecky (1996): "Macroeconomic news and the efficiency of international bond futures markets," Journal of Futures Markets, $16,131-145$.

Berkman, N. G. (1978): "On the significance of weekly changes in M1," New England Economic Review, May-June, 5-22.

Black, F. (1976): "Studies in Stock Price Volatility," in Proceedings of the 1976 Business Meeting of the Business and Economic Statistics Section, American Statitistical Association, pp. 177-181.

Bollerslev, T., J. Cai, and F. M. Song (2000): "Intraday periodicity, long memory volatility, and macroeconomic announcement effects in the US Treasury bond market," Journal of Empirical Finance, 7, 37-55.

Bollerslev, T., And J. M. Wooldridge (1992): "Quasi-Maximum Likelihood Estimation and Inference in Dynamic Models with Time-Varying Covariances," Econometric Review, 11, 143-172.

Christie, A. A. (1982): "The stochastic behavior of common stock variances - value, leverage, and interest rate effects," Journal of Financial Economics, 10, 407-432.

Christie-David, R., and M. Chaudhry (1999): "Liquidity and maturity effects around news releases," Journal of Financial Research, 22, 47-67.

Clark, P. K. (1973): "A subordinated stochastic process model with finite variance for speculative prices," Econometrica, 41, 135-155. 
CoOK, T., And S. Korn (1991): "The reaction of interest rates to the employment report: The role of policy anticipations," Economic Review, Federal Reserve Bank of Richmond, $77,3-12$.

Copeland, T. E. (1976): "A model of asset trading under the assumption of sequential information arrival," Journal of Finance, 31, 1149-1168.

- (1987): "The effect of sequential information arrival on asset prices: An experimental study," Journal of Finance, 42, 763-797.

Crain, S. J., and J. H. LeE (1995): "Intraday volatility in interest rate and foreign exchange spot and futures markets," Journal of Futures Markets, 15, 395-421.

Dacorogna, M. M., U. A. Müller, R. J. Nagler, R. B. Olsen, and O. V. Pictet (1993): "A geographical model for the daily and weekly seasonal volatility in the foreign exchange market," Journal of International Money and Finance, 12, 413-43.

Dominguez, K. M. (1999): "The Market Microstructure of Central Bank Intervention," Discussion Paper W7337, Cambridge, MA.

DWyer, G.-P., AND R. W. HAFer (1989): "Interest rates and economic announcements," Federal Reserve Bank of St. Louis Review, 71, 34-46.

Ederington, L. H., And J. H. Lee (1993): "How markets process information: News releases and volatility," Journal of Finance, 48, 1161-1191.

- (1995): "The short-run dynamics of the price adjustment to new information," Journal of Financial and Quantitative Analysis, 31, 117-134.

EDISON, H. J. (1996): "The reaction of exchange rates and interest rates to news releases," Discussion Paper 570, Board of Governors of the Federal Reserve System.

Fleming, M. J., And E. M. Remolona (1997): "What moves the bond market," Economic Policy Review, Federal Reserve Bank of New York, December, 31-50.

(1999a): "Price formation and liquidity in the U.S. Treasury market: The response to public information," Journal of Finance, 54, 1901-1915.

- (1999b): "The term structure of announcement effects," Discussion paper, Federal Reserve Bank of New York.

Franke, G., And D. Hess (2000a): "The impact of scheduled news announcements on T-bond and Bund futures trading," in Institutional Arrangements for Global Economic Integration, ed. by H.-J. Vosgerau, pp. 337-366, MacMillan, London. 
- (2000b): "Information diffusion in electronic and floor trading," Journal of Empirical Finance, 7, 455-478.

French, K. R., W. Schwert, and R. F. Stambaugh (1987): "Expected stock returns and volatility," Journal of Financial Economics, 19, 3-30.

Goodhart, C. A. E., S. G. Hall, S. G. B. Henry, and B. Pesaran (1993): "News Effects in a High-Frequency Model of the Sterling-Dollar Exchange Rate," Journal of Applied Econometrics, 8, 1-13.

Goodhart, C. A. E., and M. O'Hara (1997): "High frequency data in financial markets: Issues and applications," Journal of Empirical Finance, 4, 73-114.

Hardouvelis, G. A. (1988): "Economic news, exchange rates, and interest rates," Journal of International Money and Finance, 7, 23-35.

HARRIS, L. (1987): "Transaction data tests of the mixture of distributions hypothesis," Journal of Financial and Quantitative Analysis, 22, 127-141.

HARris, M., ANd A. RAviv (1993): "Difference of opinion make a horse race," Review of Financial Studies, 6, 473-506.

Harvey, C. R., And R. D. Huang (1991): "Volatility in the foreign currency futures market," Review of Financial Studies, 4, 543-569.

Hess, D. (2001): "Surprises in U.S. macroeconomic releases: Determinants of their relative impact on T-Bond futures," Discussion Paper 01/01, Center of Finance and Econometrics, University of Konstanz.

Hess, D., And M. Moersch (2001): "Predictability in analysts' forecast errors: Does discreteness matter?," Working paper, University of Konstanz.

Jones, C. (1998): "The economic sources of long memory in interest rate volatility," Second International Conference on High Frequency Data in Finance, Proceedings, Vol. 2, Olsen and Associates, Zürich.

Jones, C., O. Lamont, and R. Lumsdaine (1998): "Macroeconomic news and bond market volatility," Journal of Financial Economics, 47, 315-337.

Kandel, E., and N. D. Pearson (1995): "Differential interpretation of public signals and trade in speculative markets," Journal of Political Economy, 103, 831-872.

KARPOFF, J. M. (1987): "The relation between price changes and trading volume: a survey," Journal of Financial and Quantitative Analysis, 22, 109-126. 
Lamoureux, C. G., and W. D. Lastrapes (1990): "Heteroskedasticity in stock return data: volume versus GARCH effects," Journal of Finance, 45, 221-229.

LI, L., AND R. F. Engle (1998): "Macroeconomic announcements and volatility of Treasury futures," Discussion paper, Department of Economics, University of California, San Diego Discussion Paper 98-27.

Müller, U. A., M. M. Dacorogna, R. D. Davé, R. B. Olsen, O. V. Pictet, and J. E. VON WeIzsäcker (1997): "Volatilities of different time resolutions - Analyzing the dynamics of market components," Journal of Empirical Finance, 4, 213-39.

Niemira, M. P., and G. F. Zukowski (1998): Trading the fundamentals: The trader's guide to interpreting economic indicators and monetary policy. McGraw Hill, New York.

Pagan, A. R., And G. W. Schwert (1990): "Alternative models for conditional stock volatility," Journal of Econometrics, 45, 267-290.

Pindyck, R. S. (1984): "Risk, inflation, and the stock market," American Economic Review, 74, 334-351.

PRAG, J. (1994): "The response of interest rates to unemployment rate announcements: Is there a natural rate of unemployment," Journal of Macroeconomics, 16, 171-184.

Rogers, R. M. (1998): Handbook of key economic indicators. McGraw Hill, New York, 2 edn.

URICh, T., AND P. WAChtel (1981): "Market response to the weekly money supply announcements in the 1970s," Journal of Finance, 36, 1063-1072.

- (1984): "The effects of inflation and money supply announcemnets on interest rates," Journal of Finance, 39, 1177-1188.

VARIAN, H. R. (1985): "Divergence of opinion in complete markets," Journal of Finance, $40,309-317$. 
Figure 1: 2-minute returns around employment releases

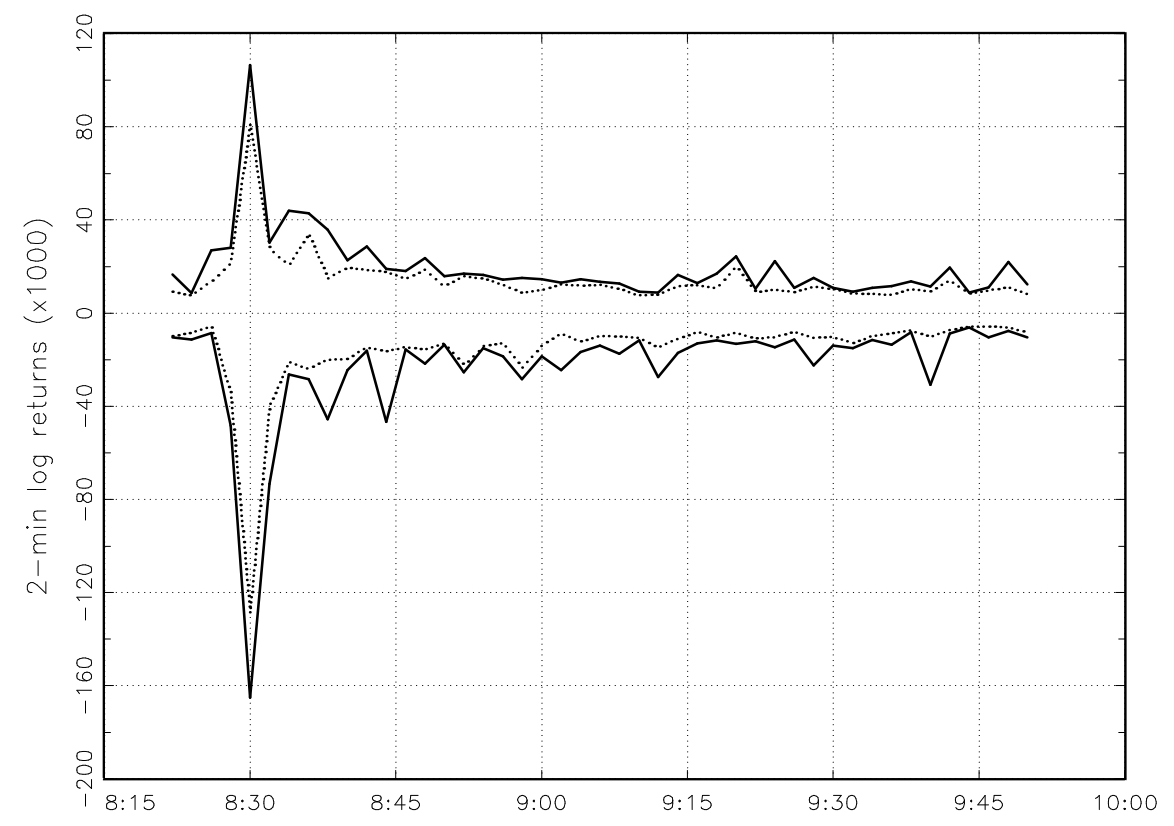

Descriptive statistics of 2-minute log returns (times 10000) during the interval 8:22 to 9:52 a.m. ET at employment announcement days are reported. The sample period is January 1995 to December 1999, resulting in 53 days at which no other macroeconomic report is released along with the employment report. $1 \%$ and $99 \%$ percentiles (solid lines) are displayed as well as $5 \%$ and $95 \%$ percentiles (dotted lines). 
Table 1: Mean function estimates

\begin{tabular}{|c|c|c|c|c|c|c|}
\hline & (1) & $(2)$ & $(3)$ & (4) & (5) & (6) \\
\hline const & -0.126 & 0.225 & 0.073 & 0.135 & 0.164 & $0.282^{*}$ \\
\hline$r_{t-1}$ & -0.027 & $-0.098^{* *}$ & -0.033 & -0.027 & $-0.095^{* *}$ & $-0.089^{* *}$ \\
\hline$S 1_{8: 28-8: 30}$ & & $-3.625^{* *}$ & & & $-4.495^{* *}$ & $-3.684^{*}$ \\
\hline$S 1_{8: 30-8: 32}$ & & $-28.692^{* * *}$ & & & $-27.897^{* * *}$ & $-26.507^{* * *}$ \\
\hline$S 1_{8: 32-8: 34}$ & & $-7.577^{* * *}$ & & & $-8.338^{* * *}$ & $-7.323^{* * *}$ \\
\hline$S 1_{8: 34-8: 36}$ & & 0.092 & & & 0.906 & \\
\hline$\left|S 1_{8: 28-8: 30}\right|$ & & -1.625 & & & -1.538 & \\
\hline$\left|S 1_{8: 30-8: 32}\right|$ & & $-11.494^{*}$ & & & -11.262 & -3.000 \\
\hline$\left|S 1_{8: 32-8: 34}\right|$ & & $-7.093^{* * *}$ & & & $-10.391^{* * *}$ & $-7.035^{* * *}$ \\
\hline$\left|S 1_{8: 34-8: 36}\right|$ & & 1.391 & & & 1.377 & \\
\hline$S 28: 28-8: 30$ & & & -1.279 & & -2.809 & \\
\hline$S 2_{8: 30-8: 32}$ & & & $26.156^{* * *}$ & & $20.004^{* * *}$ & $18.867^{* * *}$ \\
\hline$S 28: 32-8: 34$ & & & 1.002 & & 0.490 & \\
\hline$S 2_{8: 34-8: 36}$ & & & 1.852 & & 2.086 & \\
\hline$\left|S 2_{8: 28-8: 30}\right|$ & & & -2.395 & & -3.385 & \\
\hline$\left|S 2_{8: 30-8: 32}\right|$ & & & -1.164 & & 3.560 & \\
\hline$\left|S 2_{8: 32-8: 34}\right|$ & & & -2.256 & & 0.179 & \\
\hline$\left|S 2_{8: 34-8: 36}\right|$ & & & 1.924 & & 1.549 & \\
\hline$S 38: 28-8: 30$ & & & & 2.476 & 0.673 & \\
\hline$S 38: 30-8: 32$ & & & & $-16.348^{*}$ & $-28.342^{* * *}$ & $-23.907^{* * *}$ \\
\hline$S 38: 32-8: 34$ & & & & 1.861 & -3.131 & \\
\hline$S 38: 34-8: 36$ & & & & 0.082 & 0.640 & \\
\hline$\left|S 3_{8: 28-8: 30}\right|$ & & & & -2.567 & 2.586 & \\
\hline$\left|S 3_{8: 30-8: 32}\right|$ & & & & -7.250 & 11.540 & \\
\hline$\left|S 3_{8: 32-8: 34}\right|$ & & & & -4.016 & 6.542 & \\
\hline$\left|S 3_{8: 34-8: 36}\right|$ & & & & 1.360 & -1.238 & \\
\hline $\bar{R}^{2}$ & 0.001 & 0.181 & 0.136 & 0.058 & 0.324 & 0.312 \\
\hline regular F-test & 0.360 & $6.045^{* * *}$ & $2.200^{* *}$ & 0.788 & $4.346^{* * *}$ & $12.137^{* * *}$ \\
\hline $\mathrm{BIC}$ & -0.004 & 0.023 & 0.022 & 0.022 & 0.076 & 0.019 \\
\hline
\end{tabular}

OLS regressions of 2-minute log returns at employment report announcement days. The sample period is January 1995 to December 1999. 53 days are used at which no other report is announced along with the employment report. For each of these days the intraday interval 8:22-9:52 ET is analyzed. The adjusted coefficient of determination $\left(\bar{R}^{2}\right)$ is given as well as the results of a regular F-test on the hypothesis of a zero coefficient vector. The Bayes information criterion (BIC) is also provided. Inference is based on heteroskedasticity robust standard errors. ${ }^{* * *},{ }^{* *}$, and ${ }^{*}$ indicates significance at the $1 \%, 5 \%$, and $10 \%$ level, respectively. 
Table 2: Simultaneous estimation of the mean and variance function

\begin{tabular}{|c|c|c|c|c|c|c|}
\hline & (1) & $(2)$ & (3) & (4) & $(5)$ & (6) \\
\hline \multicolumn{7}{|l|}{ Mean: } \\
\hline const & 0.325 & $0.161^{*}$ & $0.186^{*}$ & $0.207^{* *}$ & $0.209^{* *}$ & $0.213^{* *}$ \\
\hline$r_{t-1}$ & $-0.119^{* * *}$ & $-0.101^{* * *}$ & $-0.102^{* * *}$ & $-0.104^{* * *}$ & $-0.104^{* * *}$ & $-0.106^{* * *}$ \\
\hline$S 1_{8: 28-8: 30}$ & $-14.742^{* *}$ & $-3.586^{* *}$ & $-3.455^{* *}$ & $-3.116^{* *}$ & $-3.051^{*}$ & $-2.830^{*}$ \\
\hline$S 1_{8: 30-8: 32}$ & $-33.079^{* * *}$ & $-24.799^{* * *}$ & $-22.937^{* * *}$ & $-23.769^{* * *}$ & $-22.398^{* * *}$ & $-22.744^{* * *}$ \\
\hline$S 1_{8: 32-8: 34}$ & -5.898 & $-4.860^{*}$ & $-4.252^{* *}$ & $-4.816^{* *}$ & $-4.169^{* *}$ & $-4.779^{*}$ \\
\hline$\left|S 1_{8: 30-8: 32}\right|$ & -2.267 & -1.112 & -1.075 & -1.006 & -1.450 & -0.479 \\
\hline$\left|S 1_{8: 32-8: 34}\right|$ & $-8.093^{*}$ & $-6.607^{* * *}$ & $-6.289^{* * *}$ & $-6.983^{* * *}$ & $-6.375^{* * *}$ & $-6.913^{* * *}$ \\
\hline$S 2_{8: 30-8: 32}$ & $18.670^{* *}$ & $20.417^{* * *}$ & $19.254^{* * *}$ & $19.398^{* * *}$ & $19.255^{* * *}$ & $18.036^{* * *}$ \\
\hline$S 38: 30-8: 32$ & $-19.893^{* * *}$ & $-24.634^{* * *}$ & $-24.839^{* * *}$ & $-23.790^{* * *}$ & $-24.267^{* * *}$ & $-21.683^{* * *}$ \\
\hline \multicolumn{7}{|l|}{ Variance: } \\
\hline const & $3.934^{* * *}$ & $3.047^{* * *}$ & $2.513^{* * *}$ & $2.989^{* * *}$ & $2.608^{* * *}$ & $2.560^{* * *}$ \\
\hline$\varepsilon_{t-1}^{2}$ & $0.502^{* *}$ & $0.113^{* * *}$ & $0.096^{* * *}$ & $0.082^{* * *}$ & $0.084^{* * *}$ & $0.085^{* * *}$ \\
\hline$\varepsilon_{t-2}^{2-1}$ & 0.037 & $0.045^{* *}$ & $0.027^{*}$ & $0.033^{* *}$ & $0.024^{*}$ & $0.022 *$ \\
\hline$\varepsilon_{t-3}^{2-2}$ & 0.032 & $0.027^{*}$ & 0.020 & 0.025 & 0.020 & 0.016 \\
\hline$D_{8: 26-8: 28}$ & & $0.692^{* *}$ & $0.712^{* *}$ & $0.633^{* *}$ & $0.684^{* *}$ & $0.686^{* *}$ \\
\hline$D_{8: 28-8: 30}$ & & $2.000^{* * *}$ & $2.000^{* * *}$ & $1.979^{* * *}$ & $1.967^{* * *}$ & $1.949^{* * *}$ \\
\hline$D_{8: 30-8: 32}$ & & $4.140^{* * *}$ & $4.091^{* * *}$ & $4.076^{* * *}$ & $4.072^{* * *}$ & $4.154^{* * *}$ \\
\hline$D_{8: 32-8: 34}$ & & $2.125^{* * *}$ & $2.246^{* * *}$ & $2.229^{* * *}$ & $2.283^{* * *}$ & $2.365^{* * *}$ \\
\hline$D_{8: 34-8: 36}$ & & $1.045^{* * *}$ & $1.240^{* * *}$ & $1.136^{* * *}$ & $1.270^{* * *}$ & $1.341^{* * *}$ \\
\hline$D_{8: 36-8: 38}$ & & $2.275^{* * *}$ & $2.358^{* * *}$ & $2.271^{* * *}$ & $2.339^{* * *}$ & $2.373^{* * *}$ \\
\hline$D_{8: 38-8: 40}$ & & $1.649^{* * *}$ & $1.610^{* * *}$ & $1.638^{* * *}$ & $1.645^{* * *}$ & $1.693^{* * *}$ \\
\hline$D_{8: 40-8: 42}$ & & $1.212^{* * *}$ & $1.192^{* * *}$ & $1.239^{* * *}$ & $1.223^{* * *}$ & $1.255^{* * *}$ \\
\hline$D_{8: 42-8: 44}$ & & $1.120^{* * *}$ & $1.152^{* * *}$ & $1.095^{* * *}$ & $1.130^{* * *}$ & $1.169^{* * *}$ \\
\hline$D_{8: 44-8: 50}$ & & $1.256^{* * *}$ & $1.231^{* * *}$ & $1.230^{* * *}$ & $1.244^{* * *}$ & $1.269^{* * *}$ \\
\hline$D_{8: 50-9: 00}$ & & $0.757^{* * *}$ & $0.821^{* * *}$ & $0.746^{* * *}$ & $0.802^{* * *}$ & $0.833^{* * *}$ \\
\hline$D_{9: 00-9: 10}$ & & $0.417^{* * *}$ & $0.475^{* * *}$ & $0.437^{* * *}$ & $0.474^{* * *}$ & $0.518^{* * *}$ \\
\hline$D_{9: 10-9: 20}$ & & $0.322^{*}$ & $0.365^{* *}$ & $0.313^{* *}$ & $0.358^{* *}$ & $0.377^{* * *}$ \\
\hline$D_{9: 20-9: 30}$ & & 0.217 & 0.199 & 0.230 & $0.210^{*}$ & $0.243^{*}$ \\
\hline$D_{9: 30-9: 40}$ & & -0.076 & -0.019 & -0.070 & -0.027 & -0.024 \\
\hline$|S 1|$ & & & $0.158^{* *}$ & & $0.161^{* * *}$ & $0.217^{* * *}$ \\
\hline$|S 2|$ & & & $0.083^{*}$ & & 0.073 & $0.090^{*}$ \\
\hline$|S 3|$ & & & $0.462^{* * *}$ & & $0.281^{* * *}$ & $0.269^{* * *}$ \\
\hline$S 1$ & & & & $0.223^{* * *}$ & $0.174^{* * *}$ & $0.212^{* * *}$ \\
\hline$S 2$ & & & & -0.021 & -0.008 & -0.013 \\
\hline$S 3$ & & & & $0.271^{* * *}$ & $0.167^{* * *}$ & $0.167^{* * *}$ \\
\hline$I_{8: 30-8: 38}^{S 1^{++}}$ & & & & & & $-1.674^{* * *}$ \\
\hline$I_{8: 40-8: 20}^{S 1^{++} S 2^{-}}$ & & & & & & $-0.475^{*}$ \\
\hline $\mathrm{BIC}$ & 7.235 & 6.820 & 6.795 & 6.798 & 6.793 & 6.795 \\
\hline$\alpha_{0}$ & $43.606^{* * *}$ & -4.354 & -4.584 & -5.337 & -4.566 & -11.330 \\
\hline$\alpha_{1}$ & $0.477^{* * *}$ & 1.024 & 1.040 & 1.046 & 1.039 & $1.126^{* * *}$ \\
\hline$F_{\alpha_{0}=0, \alpha_{1}=1}$ & $7.619^{* * *}$ & 0.569 & 0.302 & 0.295 & 0.203 & 0.447 \\
\hline$R^{2}$ & 0.060 & 0.229 & 0.242 & 0.249 & 0.250 & 0.287 \\
\hline
\end{tabular}

Maximum Likelihood estimation of 2-minute log returns at employment report announcement days (sample period: January 1995 to December 1999, i.e. 53 non-overlapping employment announcement days). For each day the intraday interval 8:22-9:52 ET is analyzed. The Bayes information criterion (BIC) as well as the $R^{2}$ from the regression $\hat{\varepsilon}_{t}^{2}=a_{0}+a_{1} \hat{h}_{t}+\nu_{t}$ is given along with the results of an F-test on the joint hypothesis of $a_{0}=0$ and $a_{1}=1\left(F_{\alpha_{0}=0, \alpha_{1}=1}\right)$. Inference is based on pseudo ML standard errors (Bollerslev and Wooldridge 1992). 
Table 3: Simultaneous estimation of the mean and variance response to the announcement of the NAPM index, consumer prices, and housing starts.

\begin{tabular}{|c|c|c|c|c|}
\hline & $\begin{array}{c}(1) \\
\text { NAPM }\end{array}$ & $\begin{array}{c}(2) \\
\text { Overall CPI }\end{array}$ & $\begin{array}{c}(3) \\
\text { Core CPI }\end{array}$ & $\begin{array}{l}(4) \\
\mathrm{HS}\end{array}$ \\
\hline \multicolumn{5}{|l|}{ Mean: } \\
\hline const & 0.123 & -0.006 & -0.019 & 0.015 \\
\hline$r_{t-1}$ & $-0.081^{* *}$ & $-0.173^{* * *}$ & $-0.171^{* * *}$ & $-0.176^{* * *}$ \\
\hline$S 1_{8: 28-8: 30}$ & $-4.806^{* *}$ & -0.453 & $-1.241^{* *}$ & -0.175 \\
\hline$S 1_{8: 30-8: 32}$ & $-7.156^{*}$ & $-6.953^{* * *}$ & $-6.116^{* * *}$ & $-8.282^{* * *}$ \\
\hline$S 1_{8: 32-8: 34}$ & $-10.701^{* * *}$ & $-3.855^{*}$ & -2.000 & -0.389 \\
\hline$\left|S 1_{8: 30-8: 32}\right|$ & -2.735 & $-5.479^{* * *}$ & -2.093 & 1.777 \\
\hline$\left|S 1_{8: 32-8: 34}\right|$ & $-9.098^{* * *}$ & $-6.295^{* *}$ & $-2.704^{*}$ & $1.204^{*}$ \\
\hline \multicolumn{5}{|l|}{ Variance: } \\
\hline const & $2.963^{* * *}$ & $2.153^{* * *}$ & $2.131^{* * *}$ & $2.362^{* * *}$ \\
\hline$\varepsilon_{t-1}^{2}$ & 0.042 & $0.104^{* * *}$ & $0.092^{* * *}$ & $0.064^{* *}$ \\
\hline$\varepsilon_{t-2}^{2}$ & -0.029 & $0.047^{*}$ & 0.045 & 0.019 \\
\hline$\varepsilon_{t-3}^{2}$ & 0.057 & 0.018 & 0.030 & -0.003 \\
\hline$D_{8: 26-8: 28}$ & 0.815 & $0.582^{* *}$ & $0.627^{* *}$ & $-0.496^{* *}$ \\
\hline$D_{8: 28-8: 30}$ & $0.941^{* *}$ & -0.251 & -0.478 & 0.176 \\
\hline$D_{8: 30-8: 32}$ & $2.324^{* * *}$ & $2.255^{* * *}$ & $2.209^{* * *}$ & $2.109^{* * *}$ \\
\hline$D_{8: 32-8: 34}$ & $2.062^{* * *}$ & $2.482^{* * *}$ & $2.649^{* * *}$ & $0.958^{* * *}$ \\
\hline$D_{8: 34-8: 36}$ & $1.634^{* * *}$ & $1.275^{* * *}$ & $1.171^{* * *}$ & $1.111^{* * *}$ \\
\hline$D_{8: 36-8: 38}$ & 0.722 & $0.598^{*}$ & $1.053^{* *}$ & -0.185 \\
\hline$D_{8: 38-8: 40}$ & $1.098^{* *}$ & $2.081^{* * *}$ & $2.111^{* * *}$ & $0.687^{* * *}$ \\
\hline$D_{8: 40-8: 42}$ & 0.186 & $1.251^{* * *}$ & $1.249^{* * *}$ & 0.195 \\
\hline$D_{8: 42-8: 44}$ & -0.445 & $1.029^{* *}$ & $0.927^{* *}$ & 0.018 \\
\hline$D_{8: 44-8: 50}$ & 0.374 & 0.390 & 0.389 & $0.311^{* *}$ \\
\hline$D_{8: 50-9: 00}$ & -0.015 & $0.499^{* *}$ & $0.484^{* *}$ & $0.255^{*}$ \\
\hline$D_{9: 00-9: 10}$ & -0.037 & 0.027 & -0.022 & -0.158 \\
\hline$D_{9: 10-9: 20}$ & $-0.731^{* *}$ & 0.141 & 0.098 & 0.031 \\
\hline$D_{9: 20-9: 30}$ & $-0.761^{* * *}$ & -0.205 & -0.211 & $-0.400^{* * *}$ \\
\hline$D_{9: 30-9: 40}$ & -0.251 & 0.076 & 0.098 & $-0.266^{* *}$ \\
\hline$|S 1|$ & $0.554^{* *}$ & $0.195^{* *}$ & $0.221^{* * *}$ & $0.172^{* * *}$ \\
\hline$S 1$ & $0.791^{* * *}$ & $0.083^{*}$ & $0.102^{* *}$ & $0.075^{* *}$ \\
\hline $\mathrm{BIC}$ & 6.205 & 5.892 & 5.890 & 5.616 \\
\hline$\alpha_{0}$ & $17.727^{* * *}$ & -3.410 & -0.718 & $-2.277^{*}$ \\
\hline$\alpha_{1}$ & $0.384^{* * *}$ & $1.189^{* *}$ & 1.053 & $1.142^{* *}$ \\
\hline$F_{\alpha_{0}=0, \alpha_{1}=1}$ & $6.422^{* * *}$ & 0.262 & 0.031 & 0.253 \\
\hline$R^{2}$ & 0.040 & 0.219 & 0.201 & 0.209 \\
\hline
\end{tabular}

Maximum Likelihood estimation of 2-minute log returns during 90-minute intervals around the announcements of the National Association of Purchasing Managers (NAPM) index, consumer prices (CPI), and housing starts (HS). The CPI report contains two headline figures, i.e. the overall index and a core index. During the sample period, January 1995 to December 1999, we observe 12 NAPM, 17 CPI, and 41 HS announcements without an overlap with other releases. For further details see table 2 . 